\title{
Child Accident Prevention Trust in Northern Ireland
}

\author{
Rosie Mercer
}

Each year in Northern Ireland (NI) approximately 40 children under 16 years of age die and almost 4000 are admitted to hospital from injuries sustained in accidents. Northern Ireland has a higher child population than the rest of the UK with $24 \%$ of its population aged under 14 years. The population is also more disadvantaged in socioeconomic terms with average annual household income $6 \%$ less than for the rest of the UK. These combine to make the NI accident problem more significant than elsewhere in the UK.

In December 1993 the Child Accident Prevention Trust (CAPT) opened an office in Belfast when funding made it possible to appoint a child safety development officer for Northern Ireland. This brief report outlines how this came about, how CAPT has successfully maintained a presence in the province, and the type of activity that we have undertaken since then.

\section{Getting started}

CAPT was already known in the province having used local contacts for the purposes of undertaking some research, and individuals attended CAPT run conferences in England. The Department of Health and Social Services (DHSS)(NI) strategy published in 1992 had highlighted accident prevention as a key method of reducing inequality in health. The department was represented on the steering group of the 'Play It Safe!' campaign-a two year campaign that strengthened CAPT's credentials.

\section{FUNDING}

At the same time CAPT was developing the idea of creating a series of nationally based development officer posts so that the demands of each region of the UK could be met and local opportunities capitalised upon. Negotiations with the Health Promotion Policy Branch of the DHSS(NI) were started with a view to funding the NI position. Capitalising on an excellent local contact within the health service, who lobbied on our behalf, the outcome was a firm offer of a grant for one year, with a view to renewing it for a further year. In addition a significant donation was given by British Telecom (NI) Community Affairs Fund.

\section{STAFFING}

This is where I came into the picture. My first foray into this subject area was as coordinator for a hospital based child injury research study, which had given me a good grounding in the subject and the start of a network of other interested professionals. To work remotely from CAPTs office in London required the 'right' person and they were prepared to wait until I had completed the research report.

\section{OFFICE PREMISES}

Our friend in the health service provided us with an office within the Department of Epidemiology and Public Health at Queen's University Belfast for a very modest fee. On the site of the Royal Group of Hospitals where much of my previous work had taken place, it was also ideally suited to make use of the medical library facilities of the university.

\section{The aims of the project}

The aims were:

(1) To create opportunities to promote the accident prevention objectives of the DHSS(NI) Regional Strategy

(2) To promote joint working in taking child safety foward

(3) To raise the profile of the subject as effectively as possible.

\section{Activities}

The essence of the project was that it should be locally driven and responsive to local need. We brought key players together, some for the first time, to a child safety planning meeting two months after establishing the office. Identification of gaps such as lack of comprehensive data, the need for strategic direction, and improved sharing and dissemination of information helped us to direct our work.

Guided by CAPT's national programme I also promoted Child Safety Week among local practitioners and in 1996 the Belfast Home Safety Committee organised filming for five 4 minute slots on our local television station. Making careful use of my time I undertake a limited number of talks, mainly to groups of other professionals, where the information can cascade to others. I am now a new and regular feature for the fourth year medical students during their lectures on public health issues. Some small scale studies have been undertaken such as children's use of bicycles and an accident survey in a housing development.

Scanning journals and local newspapers for articles, collecting reports and resources from 
various organisations, and acquiring what accident data are available are ongoing tasks. These satisfy most of the requests for information that I receive from students, healthcare workers, and schoolchildren. A presence for CAPT on the Internet is planned and web pages are under construction.

As our core funding is never long term I have had to spend quite a lot of my time developing project proposals and applying for funding-you will all be familiar with this. One which paid off with a small grant from the Rural Development Council will be developing farm safety checklists.

\section{Highlights to date}

Piggybacking on the launch of Injury Prevention in London in March 1995, we cajoled Barry Pless, Terry Nolan, and Sue Gallagher to travel to NI to speak on the themes of data collection and effective interventions. It proved to be a very successful conference attracting a number of delegates from the Republic of Ireland, links which have since developed into a national accident forum.

In February 1996 I attended the Third International Conference on Injury Prevention and Control in Melbourne. Funded by the DHSS(NI) it is proof that begging letters can work-as long as there is justification for what you are begging and you have good timing.

I was successful in my application for a
Winston Churchill Travelling Fellowship in 1996, enabling me to return to Australia for an extended visit to look at injury surveillance systems and accident prevention programmes. A once in a lifetime opportunity, so it worthwhile applying for such schemes.

The allocation of further grants from the DHSS (NI) has been very encouraging for us $\frac{\text { ? }}{7}$ we consider it to be tacit approval for our wor and future plans.

\section{Future aspirations}

'If I had a dream...' it would be a child safe centre for Belfast. With facilities and service $\bar{s}$ based on those which I visited in Australia, $\mathscr{S}^{\circ}$ believe that such a facility would become $\bar{c}$ focal point for a number of agencies, providing a high profile face for accident prevention. feel that the following statement from one of the speakers at the Melbourne Conference sums up what we've been trying to do:

- Get a committed individual and a home $\vec{c}$

- Spend time listening and watching what $\frac{\mathbb{8}}{8}$ happening

- Start small and build up a good track recor of work

- Develop your network

- Be competent and appear competent

- Get noticed-both publicly and profession? ally.

What will 1997 bring?

\section{Editorial Board Member: brief biography}

\section{PETER WRIGHT}

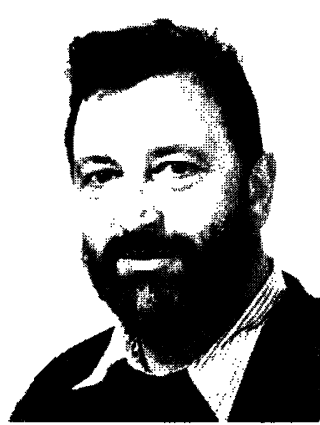

Peter Wright graduated from the University in Oxford in 1964 after taking moderations in biochemistry and finals in philosophy, physiology, and psychology. He went to Yale University as a Fulbright scholar and held a US Public Health Service predoctoral fellowship with Dr Irving Janis returning to Oxford and completing his doctorate in 1969 . He was lecturer in psychology at Oriel College, Oxford before appointment as a lecturer and now senior lecturer in psychology at the University of Edinburgh. After working for some years on problems of physiological psychology, he became interested in developmental psychology, especially in the development of feeding in early infancy. In recent years he has been especially interested in applied issues in child development, and was a founder member of the Edinburgh Centre for Research in Child Development. $\mathrm{He}$ is a chartered psychologist and Fellow of the British Psychological Society. 